\title{
"You Might Belong in Gryffindor": Children's Courage and Its Relationships to Anxiety Symptoms, Big Five Personality Traits, and Sex Roles
}

\author{
Peter Muris • Birgit Mayer · Tinke Schubert
}

Published online: 14 October 2009

(C) The Author(s) 2009. This article is published with open access at Springerlink.com

\begin{abstract}
This study describes a first exploration of the construct of courage in youths. Children aged 8-13 years were invited to report on the most courageous action that they had ever performed during their life. In addition, the Courage Measure for Children (CM-C) was construed as an index of children's level of personal courage, and this scale was administered in two samples of school children ( $N$ s being 168 and 159) along with a number of other questionnaires. Results indicated that children were familiar with the concept of courage as more than $70 \%$ reported to have carried out a courageous action during their life. In addition, self-reported courage as indexed by the CM-C was positively correlated with scores on a vignette measure of courage, parent ratings of children's courage, extraversion, openness/intellect, and a masculine sex role, whereas a negative correlation was observed with anxiety symptoms. The implications of these findings and potential directions for future research are briefly discussed.
\end{abstract}

Keywords Courage $\cdot$ Fear and anxiety $\cdot$ Personality traits $\cdot$ Sex roles Children

\section{Introduction}

An overview of the psychological literature indicates that little is known about the construct of courage, and this is especially true for children [1]. The most extensive research on this topic has been conducted by Rachman and colleagues [2-4] who defined courage as behavioral approach despite the experience of fear. This definition was mainly based on studies of paratrooper soldiers who were closely followed during their training program.

Quotation from J.K. Rowling's (1997) Harry Potter and the philosopher's stone in which Gryffindor refers to the school department at Hogwarts School of Witchcraft and Wizardry, which consists of children with an extremely courageous personality.

P. Muris $(\bowtie) \cdot$ B. Mayer · T. Schubert

Institute of Psychology, Erasmus University Rotterdam, Burgemeester Oudlaan 50, Suite T13-37,

P.O. Box 1738, 3000 DR Rotterdam, The Netherlands

e-mail: muris@fsw.eur.nl 
Some of the paratroopers were defined as fearful: that is, these soldiers showed high levels of physiological arousal and failed to perform their jump. In contrast, there were paratroopers who exhibited no noteworthy arousal and smoothly carried out the jump. Most importantly, there was also a group of paratroopers who displayed similar high levels of arousal as the fearful group, but nevertheless successfully completed the jump. These 'courageous' paratrooper soldiers performed the same action as their fearless colleagues in spite of experiencing fear.

Although not all researchers hold this same definition (e.g., [5, 6]), Rachman's [1, 7] conceptualization of courage as approach behavior in combination with fear seems to be particularly relevant from a clinical perspective. To begin with, according to behavior theory, courage may interfere with the development of pathological fear and anxiety. More precisely, when facing threat, those who engage in courageous behavior by exposing themselves to the feared stimulus or situation, are less likely to develop anxiety problems. In contrast, those who display a tendency to avoid will show a continuation and exacerbation of their fears [8]. In a similar vein, courageous behavior can be considered as important during the treatment of anxiety disorders, in which exposure to (and approach of) the feared or anxiety-eliciting stimulus or situation is considered as a crucial element (e.g., [9]).

Thus, individual differences in courage might play a role during the development and treatment of anxiety problems. Evidence for this idea comes from a recent study by Norton and Weiss [10] who developed the Courage Measure (CM), a brief self-report scale for assessing courage, and then examined its relationships to fear and approach behavior in a small sample of spider fearful women. The results showed that the CM was a reliable scale that showed a negative correlation to self-reported spider fear and a positive correlation to performance on a behavioral test during which participants had to approach a taxidermied tarantula. Most interestingly, after controlling for self-reports of spider fear, CM scores remained significantly linked to approach behavior, such that participants with greater courage moved closer to the spiders.

Given the relevance of courage within the context of (clinical) fear and anxiety, and acknowledging the fact that many anxiety problems already tend to arise at a fairly young age [11], it seems worthwhile to examine this concept in young people. With this in mind, the present study was set up as a first exploration of the construct of courage in youths. School children aged 8-13 years were asked to report on the most courageous action(s) that they had ever performed during their life. Further, an age-downward version of the $\mathrm{CM}$ was construed (i.e., the $\mathrm{CM}$ for Children or, briefly, CM-C). The $\mathrm{CM}-\mathrm{C}$ was administered in two independent samples of children along with a vignette task that also measured courageous behaviors and a number of other questionnaires for assessing Big Five personality traits, anxiety symptoms, social desirability, and sex roles. In spite of the explorative nature of the study, we expected courage as indexed by the $\mathrm{CM}-\mathrm{C}$ to be positively linked with (a) extraversion as this personality trait might be associated with a tendency to appraise events as challenging and controllable and reliance on problem-focused coping strategies [12], and (b) a masculine sex role as courage seems to be a key feature of manliness [13]. In contrast, negative associations were expected to be found between courage and anxiety symptoms, because the demonstration of such symptoms does not really fit with the image of bravery and courage (although according to Rachman [1,7] courageous acts are by definition conducted while experiencing fear and anxiety). 


\section{Method}

Participants and Procedure

Two independent samples of schoolchildren were recruited for this study. Sample 1 consisted of 168 children ( 81 boys and 87 girls; mean age 9.49 years, SD $=1.12$ ) of primary schools in two small cities in the western part of The Netherlands. Sample 2 consisted of 159 children (70 boys and 89 girls; mean age 10.52 years, $\mathrm{SD}=0.97$ ) of a large primary school in Gouda, The Netherlands. The majority of the children in both samples $(>75 \%)$ was from original Dutch descent. The recruitment procedure was similar for both samples: children's parents first received information about the study along with a consent form (parents of the children in Sample 2 were also asked to complete the parent version of the CM-C). In Sample 1, the participation rate was high ( $>90 \%)$, whereas that in Sample 2 was lower but still acceptable $(>60 \%)$.

Upon agreement of their parents, children completed a set of questionnaires. This was done in classroom sessions during which a research assistant and the teacher were always present in order to ensure confidential and independent responding. Children of Sample 1 filled in the CM-C, the courage vignette measure, the most courageous action question as well as questionnaires for measuring personality traits, anxiety symptoms, and social desirability. Children of Sample 2 completed the CM-C and the sex role inventory (see below).

\section{Assessment}

The $C M-C$ is an age-downward version of the self-report scale of courage that was recently developed by Norton and Weiss [10]. The measure consists of 12 items (e.g., "I try to get over my fears", "I behave myself in a brave way", "If I am anxious about something, I will do or face it anyway", and "If something scares me, I try to get away from it" [reverse item]) that have to be rated on a 4-point Likert scale $(1=$ not true, $2=$ somewhat true, $3=$ true, and $4=$ very true). After recoding reverse items, a total courage score can be computed with higher scores being indicative of higher levels of courageous behavior. The parent version of the CM-C that was employed in Study 2 is similar to the child self-report version, except for that items are rephrased from the parents' perspective (e.g., "My child tries to get over his/her fears").

Courage was also measured by means of 12 vignettes, which were construed for the purpose of the present study. Each vignette depicts a scenario that elicits some fear and which ends with a question concerning the performance of a (courageous) behavior in the pertinent situation. An example of a vignette is: "Imagine that you are home alone in the evening. Your parents have gone to the movies and have told you that they will only be back in a few hours. It is dark outside and the wind is blowing hard around the house, and you have closed all the windows and curtains. You find it a little scary to be home alone right now. Suddenly, the door bell rings... Do you open the front door to see who is there?" Children have to answer these questions by means of 4-point scales ranging from $1=$ not at all true to $4=$ very true, with higher ratings reflecting a more brave character.

Children were asked to write down the most courageous action(s) they had performed during their live.

The Big Five Questionnaire for Children (BFQ-C; [14]) is a 65-item questionnaire for measuring the five basic factors of personality (i.e., the Big Five) in children and adolescents: (1) extraversion which refers to aspects such as activity, enthusiasm, 
assertiveness, and self-confidence, (2) agreeableness which reflects concern and sensitivity towards others and their needs, (3) conscientiousness which has to do with dependability, orderliness, precision, and the fulfilling of commitments, (4) neuroticism which pertains to a proneness to experience feelings of anxiety, depression, discontent, and anger, and (5) openness/intellect which is concerned with intellectual functioning, creativity, imagination, and social and cultural interest. Items have to be scored on a 5-point Likert scale ranging from $1=$ almost never to $5=$ almost always. Individual item scores are combined to yield a total score for each of the five factors. Clear support has been found for the psychometric qualities of the BFQ-C in children and adolescents [14, 15].

The Screen for Child Anxiety Related Emotional Disorders (SCARED; [16]) is a selfreport questionnaire for measuring anxiety disorder symptoms in children and adolescents. The scale consists of 41 items that can be allocated to five subscales: panic/somatic (e.g., "When frightened, my heart beats fast"), generalized anxiety (e.g., "I am a worrier"), separation anxiety (e.g., "I don't like being away from my family"), social phobia (e.g., "I don't like to be with unfamiliar people"), and school phobia (e.g., "I am scared to go to school"). Children are asked to rate the frequency with which they experience each symptom using three-point scales $(0=$ almost never, $1=$ sometimes, and $2=$ often $)$. A SCARED total score was obtained by summing across all items. Research has demonstrated that the SCARED has good internal consistency, test-retest reliability, and validity, and this conclusion appears true for clinical as well as non-clinical samples of youths [16, 17].

Social desirability was measured with a subscale from the Amsterdamse Biografische Vragenlijst voor Kinderen (Amsterdam Biographical Questionnaire for Children-ABVK; [18]). Seven items such as "I always think friendly about everyone" and "I am always obedient at home" have to be answered with yes or no, with the total of affirmative responses yielding a score, which is indicative for a socially desirable attitude.

The Children's Sex Role Inventory (CSRI; [19]) is a self-report questionnaire for measuring gender role orientation. The CSRI contains 11 masculinity (e.g., "When I play games, I really like to win") and 11 femininity items (e.g., "I am a kind and caring person") that have to be scored on a 4-point Likert scale $(1=$ not true, $2=$ somewhat true, $3=$ true, and $4=$ very true). Previous research has shown that the CSRI has good internal consistency and test-retest stability, and reasonable validity as established through relations with gender-typed toy and activity preferences $[19,20]$.

\section{Results}

\section{General Findings}

The majority of the children in Sample 1 (71.4\%) reported to have conducted one or more courageous action(s) sometime during their life. The most prevalent brave acts were concerned with performing a physically risky action (14.3\%), preventing injury of another person $(11.9 \%)$, and dealing with a feared animal $(8.9 \%)$. Examples of these and other courageous behaviors reported by the children are provided in Table 1. Most of the examples provided by the children indeed seemed to reflect courageous behavior, although there were also a small number of acts reported that seemed to be less clear-cut acts of courage (e.g., helping another person, engaging in unacceptable behavior, performing a difficult task). 


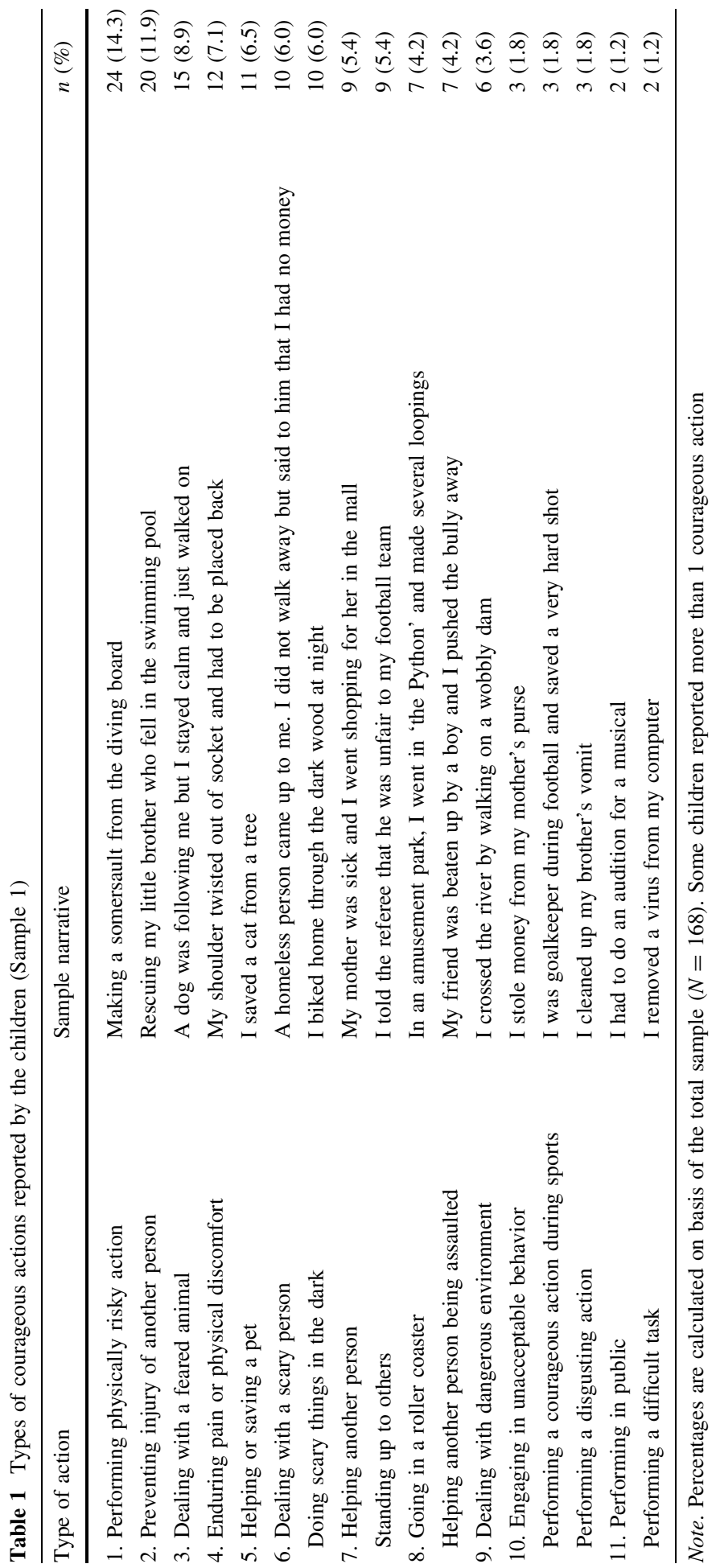


Descriptive statistics of the CM-C and other questionnaires that were administered in both samples are reported in Table 2. As can be seen, the CM-C was found to be a reliable index of children's courage, with Cronbach's alphas of 0.73 (Sample 1) and 0.86 (Sample 2 ) for the self-report version and 0.78 (Sample 2) for the parent-report version. Note in passing that all other questionnaires also displayed acceptable internal consistency coefficients $(>0.60)$, with the exception of the ABVK social desirability scale for which the alpha value was too low (i.e., $\alpha=0.40$ ).

Boys rated themselves as more courageous on the CM-C then did girls [Sample 1: $t(166)=4.72, p<0.001$; Sample 2: $t(157)=2.21, p<0.05]$, although this was not confirmed by their parents [Sample 2: $t(157)<1$ ]. A similar pattern was found on the courage vignettes task where boys reported that they were more likely to perform various courageous behaviors as compared to girls $[t(166)=2.25, p<0.05]$. Other sex differences were also found: girls described themselves as more agreeable $[t(166)=2.40$, $p<0.05]$, conscientious $[t(166)=3.72, p<0.001]$, anxious $[t(166)=3.05, p<0.01]$, and feminine $[t(157)=4.87, p<0.001]$, whereas boys rated themselves as more masculine $[t(157)=6.81, p<0.001]$. In the light of these differences, it was decided to control for sex in all further analyses.

\section{Relationships Between Courage as Indexed by the CM-C and the Other Measures}

Correlations between $\mathrm{CM}-\mathrm{C}$ scores and the other measures are reported in the most right column of Table 2. As can be seen, CM-C scores were positively related to children's responses to the courage vignettes $(r=0.46)$, indicating that our two self-report courage

Table 2 Descriptive statistics (means, standard deviations, sex differences, reliability coefficients) for the CM-C and other questionnaires as well as correlations between self-reported courage, on the one hand, and anxiety, personality, and sex role scores, on the other hand

\begin{tabular}{llllll}
\hline & Total group & Boys & Girls & $\alpha$ & $r$ with CM-C \\
\hline Sample 1 $(N=168)$ & & & & & - \\
CM-C & $32.30(6.04)$ & $33.36(5.85)_{\mathrm{a}}$ & $31.32(6.08)_{\mathrm{b}}$ & 0.73 & - \\
Courage vignettes & $35.07(5.59)$ & $36.06(5.31)_{\mathrm{a}}$ & $34.14(5.73)_{\mathrm{b}}$ & 0.64 & $0.46^{* *}$ \\
BFQ-C extraversion & $33.11(6.36)$ & $32.23(5.93)_{\mathrm{a}}$ & $33.93(6.67)_{\mathrm{a}}$ & 0.79 & $0.37^{* *}$ \\
BFQ-C agreeableness & $33.20(6.45)$ & $31.98(6.68)_{\mathrm{a}}$ & $34.34(6.05)_{\mathrm{b}}$ & 0.83 & 0.15 \\
BFQ-C conscientiousness & $34.43(6.31)$ & $32.63(6.30)_{\mathrm{a}}$ & $36.12(5.88)_{\mathrm{b}}$ & 0.81 & $0.18^{*}$ \\
BFQ-C neuroticism & $22.93(5.81)$ & $23.28(5.67)_{\mathrm{a}}$ & $22.60(5.96)_{\mathrm{a}}$ & 0.77 & 0.04 \\
BFQ-C openness/intellect & $31.44(6.36)$ & $31.37(6.42)_{\mathrm{a}}$ & $31.51(6.35)_{\mathrm{a}}$ & 0.76 & $0.33^{* *}$ \\
ABVK social desirability & $3.47(1.60)$ & $3.37(1.50)_{\mathrm{a}}$ & $3.56(1.70)_{\mathrm{a}}$ & 0.40 & -0.08 \\
SCARED total anxiety & $21.86(12.35)$ & $18.92(10.94)_{\mathrm{a}}$ & $24.60(13.00)_{\mathrm{b}}$ & 0.91 & $-0.30^{* *}$ \\
Sample 2 $(N=159)$ & & & & & - \\
CM-C & $27.68(8.18)$ & $30.92(8.27)_{\mathrm{a}}$ & $25.13(7.18)_{\mathrm{b}}$ & 0.86 & - \\
CM-C parent version & $24.09(6.45)$ & $24.56(7.40)_{\mathrm{a}}$ & $23.73(5.61)_{\mathrm{a}}$ & 0.78 & $0.45^{* *}$ \\
CSRI masculinity & $23.87(4.33)$ & $26.20(3.73)_{\mathrm{a}}$ & $22.04(3.89)_{\mathrm{b}}$ & 0.66 & $0.50^{* *}$ \\
CSRI femininity & $27.53(4.94)$ & $25.51(4.61)_{\mathrm{a}}$ & $29.11(4.63)_{\mathrm{b}}$ & 0.78 & 0.07 \\
\hline
\end{tabular}

Note. $C M-C$ Courage Measure for Children, $B F Q-C$ Big Five Questionnaire for Children, $A B V K$ Amsterdamse Biografische Vragenlijst voor Kinderen, SCARED Screen for Child Anxiety Related Emotional Disorders, CSRI Children's Sex Role Inventory. Means with different subscripts differ at $p<0.05$

$* p<0.05$, ** $p<0.001$ 
measures converged. Further, child- and parent-reported courage scores were moderately correlated $(r=0.45)$, which means that the parent-child agreement for this construct is reasonable. The hypothesized correlations were found between CM-C scores and extraversion $(r=0.37)$, masculinity $(r=0.50)$, and anxiety $(r=-0.30)$. Thus, self-reported courage was indeed associated with higher levels of extraversion and masculinity, and lower levels of anxiety symptoms. CM-C scores were also positively linked to conscientiousness $(r=0.18)$ and openness/intellect $(r=0.33)$, which means that self-reported courage is also accompanied by (somewhat) higher levels of these personality traits. Finally, CM-C scores were unrelated to social desirability, which means that children's responses to this measure are not affected by the tendency to provide a positive picture of themselves.

\section{Additional Analyses}

Two regression analyses were carried out in order to examine (1) the unique contributions of various Big Five personality traits to children's courage scores, and to explore (2) whether courage explained additional variance in children's anxiety scores beyond Big Five personality traits. In both analyses, we controlled for sex by entering this variable into the equation on step 1 . The results of the first regression analysis are displayed in Table 3 and indicate that Big Five personality traits explained a significant proportion of the variance in children's courage symptoms (i.e., $21 \%$ ). Note also that the personality traits of extraversion and openness/intellect were found to make unique positive contributions, whereas agreeableness made a negative contribution to courage. In other words, higher levels of extraversion and openness/intellect but lower levels of agreeableness were associated with higher levels of courage in children.

The second regression analysis indicated that neuroticism and extraversion accounted for unique proportions of the variance in SCARED scores (see Table 4): betas were, respectively, positive and negative, which means that higher levels of neuroticism and lower levels of extraversion were associated with higher levels of anxiety symptoms. Courage was found to explain an additional, significant proportion of the variance in SCARED scores (i.e., 5\%): the negative beta indicated that higher levels of courage were linked to lower levels of anxiety symptoms.

Table 3 Results of the regression analyses predicting courage from Big Five personality traits (Sample 1)

\begin{tabular}{|c|c|c|c|c|}
\hline & $B$ & SE & $\beta$ & $\Delta R^{2}$ \\
\hline \multicolumn{5}{|l|}{ Courage (CM-C) } \\
\hline Step 1 & & & & $0.03^{*}$ \\
\hline Sex & -2.04 & 0.92 & $-0.17 *$ & \\
\hline Step 2 & & & & $0.21 * *$ \\
\hline Extraversion & 0.40 & 0.09 & $0.42 * *$ & \\
\hline Agreeableness & -0.24 & 0.10 & $-0.26^{*}$ & \\
\hline Conscientiousness & 0.09 & 0.10 & 0.09 & \\
\hline Neuroticism & 0.02 & 0.08 & 0.02 & \\
\hline Openness/intellect & 0.20 & 0.09 & $0.21 *$ & \\
\hline
\end{tabular}

Note. $C M-C$ Courage Measure for Children

$N=168, * p<0.05, * * p<0.001$ 
Table 4 Results of the regression analyses predicting anxiety disorders symptoms from courage and Big Five personality traits (Sample 1)

\begin{tabular}{lcccc}
\hline \multicolumn{1}{c}{$B$} & SE & $\beta$ & $\Delta R^{2}$ \\
\hline $\begin{array}{l}\text { Anxiety disorder symptoms (SCARED) } \\
\text { Step 1 }\end{array}$ & & & & $0.05^{*}$ \\
$\quad$ Sex & 5.67 & 1.86 & $0.23^{*}$ & $0.36^{* *}$ \\
Step 2 & & & $-0.29^{* *}$ & \\
Extraversion & -0.56 & 0.16 & 0.10 & \\
Agreeableness & 0.19 & 0.18 & 0.05 & \\
Conscientiousness & 0.11 & 0.18 & $0.59^{* *}$ & $0.05^{* *}$ \\
Neuroticism & 1.24 & 0.14 & 0.02 & \\
$\quad$ Openness/intellect & 0.04 & 0.15 & & \\
Step 3 & & & $-0.26^{* *}$ & \\
Courage & -0.53 & 0.14 &
\end{tabular}

Note. SCARED Screen for Child Anxiety Related Emotional Disorders

$N=168, * p<0.05, * * p<0.001$

\section{Discussion}

The current study was a first attempt to explore the concept of courage in youths. The main results can be catalogued as follows. First of all, children appeared to comprehend the construct of courage: that is, the majority of them (i.e., more than $70 \%$ ) reported that they had performed one or more courageous action(s) at some time during their life. In general, the types of courageous acts mentioned by the children were highly similar to those reported by adults in the study by Pury et al. [5]. For example, the top three of children's courageous actions (i.e., 'performing physically risky action', 'preventing injury of another person', and 'dealing with a feared animal') were also commonly listed by the adults in Pury et al.'s research. Most of children's courageous acts were what Pury and colleagues defined as 'preventing physical accidents to oneself', although there were some noteworthy exceptions to this rule (e.g., 'helping or saving a pet' and 'helping another person being assaulted'). Second, it seems possible to reliably assess children's level of courage by means of an age-downward version of the CM (i.e., the CM-C), and these self-report scores also seem to possess some validity, as evidenced by positive correlations with scores on an alternative measure of courage (i.e., the vignette task) and a parent-version of the CM-C. Third and finally, as predicted, children's courage scores as indexed by the CM-C were positively linked to the personality trait of extraversion and the masculine sex role, whereas a negative relation was observed with self-reported anxiety symptoms.

With regard to the relations between personality traits and courage, it should be noted that the Big Five personality trait of openness/intellect was consistently and positively related to CM-C scores. That is, higher levels of openness/intellect were accompanied by higher levels of courage. When looking at the facets of this personality trait, this link certainly makes sense from a theoretical point-of-view. That is, openness/intellect is characterized by a tendency to value peculiar emotional states, to try new activities, to be open to new ideas, and a readiness to re-examine traditional social, religious, and political values [12], which all seem to be features that are compatible with a courageous disposition. Further, some indications were also found for a relationship between courage and 
the personality traits of conscientiousness and agreeableness. However, these links were only observed in the simple correlation analysis or they emerged when controlling for the shared variance with other personality traits (and thus might be a statistical artifact), and hence should be interpreted with caution.

The current study yielded a number of other findings that deserve brief attention. To begin with, CM-C scores were not significantly associated with social desirability, which implies that children's self-reported courage scores were not affected by a tendency to provide a positive picture of themselves. However, it should also be acknowledged that the social desirability scale that we employed was not very reliable, and so the relation between social desirability and courage remains unclear and certainly needs further exploration. In addition, the results obtained for Sample 1 indicated that the Big Five personality traits jointly accounted for $21 \%$ of the variance in courage scores. This rather modest percentage of explained variance seems to suggest that there are still a number of other variables involved in the formation of children's levels of courage. Besides a masculine sex role (Sample 2), other candidates might be sensation seeking, impulsivity, and perceived self-efficacy [1,7]. Lastly, the (negative) link between courage and anxiety symptoms was hardly affected when controlling for neuroticism and extraversion. This suggests that courage makes an independent contribution to children's anxiety symptoms besides these basic personality traits.

It should be acknowledged that the present investigation suffers from a number of limitations. In the first place, the present study relied on two samples of children with a rather restricted age range (i.e., 8-13 years), and so it remains to be seen whether courage is also a useful concept in young people of other ages. Second, the question concerning children's most courageous act was asked after the courage vignette task. This procedure was followed to ensure that children developed a good understanding of the concept of courage, but of course it is possible that children were primed by the content of the vignettes when responding to this question. Nevertheless, most responses of the children did not directly refer to the vignettes and thus seemed to reflect idiosyncratic courageous acts. Third, it should be borne in mind that this study is just as a first exploration of the construct of courage in youths. An important issue that needs to be addressed in future research is to demonstrate that self-reported courage accounts for variance in behavioral approach of a threatening stimulus or situation above-and-beyond that accounted for by pre-existing fear or anxiety levels [10]. Such evidence would confirm the notion that courage should be regarded as a potentially relevant clinical construct that might be involved in the development and treatment of phobias and other anxiety problems in youths.

\section{Summary}

This study describes a first attempt to examine the construct of courage in children aged 813 years. Results revealed that children of this age were familiar with the concept of courage as more than $70 \%$ reported to have carried out a courageous action at some time during their life. In addition, indications were found for the reliability and validity of the $\mathrm{CM}-\mathrm{C}$, a self-report scale for measuring levels of courage in children. Most interestingly from a clinical perspective, CM-C scores were negatively correlated with children's anxiety scores. That is, higher levels of courage were associated with lower levels of anxiety, and this result remained unchanged when controlling for relevant personality traits such as extraversion and neuroticism. Prospective research should investigate whether 
courage plays a role in the development of childhood phobias and anxiety disorders, and treatment studies could explore whether this variable moderates the outcome of exposurebased treatments for such problems.

Open Access This article is distributed under the terms of the Creative Commons Attribution Noncommercial License which permits any noncommercial use, distribution, and reproduction in any medium, provided the original author(s) and source are credited.

\section{References}

1. Rachman SJ (2004) Fear and courage: a psychological perspective. Soc Res 71:149-176

2. Cox D, Hallam RS, O'Connor K, Rachman SJ (1983) An experimental analysis of fearfulness and courage. Br J Psychol 74:107-117

3. McMillan TM, Rachman SJ (1988) Fearlessness and courage in paratroopers undergoing training. Pers Individ Differ 9:373-378

4. O’Connor K, Hallam RS, Rachman SJ (1985) Fearlessness and courage: a replication experiment. Br J Psychol 76:187-197

5. Pury CLS, Kowalski RM, Spearman J (2007) Distinctions between general and personal courage. J Posit Psychol 2:99-114

6. Woodard CR, Pury CLS (2007) The construct of courage: categorization and measurement. Consult Psychol J Pract Res 59:135-147

7. Rachman SJ (1984) Fear and courage. Behav Ther 15:109-120

8. Mowrer OH (1960) Learning theory and behavior. Wiley, New York

9. Marks IM (1987) Fears, phobias, and rituals. Panic, anxiety, and their disorders. Oxford University Press, New York

10. Norton PJ, Weiss BJ (2009) The role of courage on behavioral approach in a fear-eliciting situation: a proof-of-concept pilot study. J Anx Disord 23:212-217

11. Muris P (2007) Normal and abnormal fear and anxiety in children and adolescents. Elsevier, Oxford, UK

12. Matthews G, Deary IJ, Whiteman MC (2003) Personality traits, 2nd edn. Cambridge University Press, Cambridge, UK

13. Connell RW (1987) Gender and power. Cambridge University Press, Cambridge, UK

14. Barbaranelli C, Caprara GV, Rabasca A, Pastorelli C (2003) A questionnaire for measuring the big five in late childhood. Pers Individ Differ 34:645-664

15. Muris P, Meesters C, Diederen R (2005) Psychometric properties of the big five questionnaire for children (bfq-c) in a Dutch sample of young adolescents. Pers Individ Differ 38:1757-1769

16. Birmaher B, Brent D, Chiappetta L, Bridge J, Monga S, Baugher M (1999) Psychometric properties of the screen for child anxiety related emotional disorders (scared): a replication study. J Am Acad Child Adolesc Psychiatry 38:1230-1236

17. Muris P, Merckelbach H, Ollendick TH, King NJ, Bogie N (2002) Three traditional and three new childhood anxiety questionnaires: their reliability and validity in a normal adolescent sample. Behav Res Ther 40:753-772

18. Van Dijl H, Wilde G (1982) Handleiding bij de amsterdamse biografische vragenlijst voor kinderen, abvk, en de korte amsterdamse biografische vragenlijst voor kinderen, kabvk. F. van Rossen, Amsterdam

19. Boldizar JP (1991) Assessing sex typing and androgyny in children: the children's sex role inventory. Dev Psychol 27:505-515

20. Muris P, Meesters C, Knoops M (2005) The relation between gender role orientation and fear and anxiety in non-clinic referred children. J Clin Child Adolesc Psychol 34:326-332 